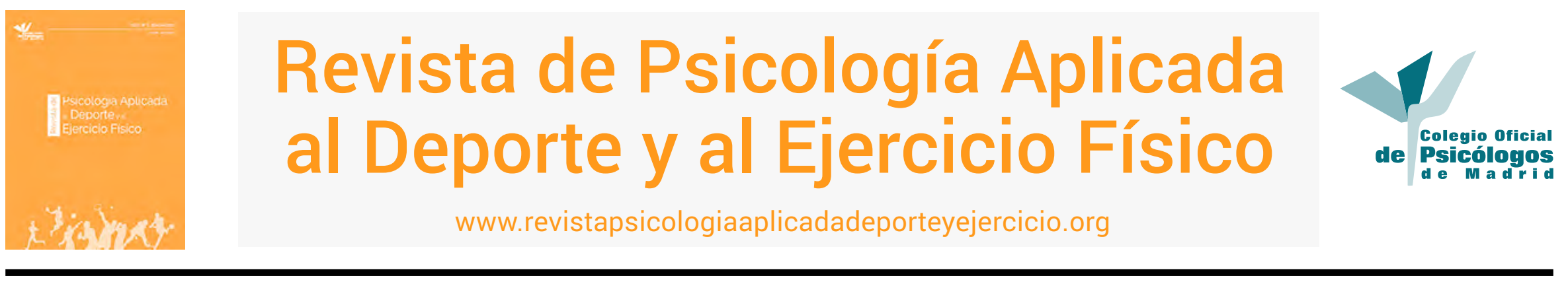

\title{
Diseño del entrenamiento mental del tenista. De lo científico a lo aplicado
}

\author{
Juan González Hernández \\ Universidad de Granada, España
}

RESUMEN: En la constante búsqueda de la mejora deportiva, el deportista que busca el rendimiento, realiza permanentes evaluaciones y reevaluaciones de su ejecución, focalizada en la repercusión que dichas ejecuciones tendrán para su competición. El deportista cuando entrena, se centra en procesos de mejora sobre la percepción de competencia y la eficacia en su rendimiento. En el presente trabajo se expone una planificación deportiva en tenistas donde se tienen en cuenta diferentes procesos de entrenamiento psicológico, la autoevaluación continua del deportista que le debe permitir hacerse consciente de sus señales, de su conexión pensamiento-emociónconducta, la autoobservación de elementos que permitirán fijar intereses, señales útiles y prioridades y la autopercepción en su gestión integral, que influye directamente en el desarrollo de sus recursos psicológicos conforme vaya observando aspectos de él/ella mismo/a a potenciar. En el tenis, la gestión de la fortaleza mental requiere de una adaptación permanente durante el periodo de entrenamiento, derivada de un entrenamiento psicológico dirigido y planeado, a la mejora del rendimiento, priorizando la adaptación permanente del desarrollo de la personalidad, el autoconcepto y el control emocional a las necesidades competitivas individuales de cada tenista.

PALABRAS CLAVES: Autorregulación, emociones, entrenamiento psicológico, personalidad, tenis.

\section{Mental Training of the Tennis Player. From Theory to Practice}

ABSTRACT: In the constant search for improvement in sport, athletes who seek performance continuously assesses and reassesses their performance thinking of the impact it will have in competition. During training, athletes focus on improving processes on the perception of competition and efficiency in performance. This paper discusses a sport planning for tennis players including different psychological training processes, continuous self-evaluation of the athlete that should allow him/her to become aware of his/her signals, the thoughtemotion-behavior connection, self-observation of elements that will allow for establishing interests, useful signals, and priorities, and self-perception in its overall management, which has a direct influence on the development of his/her psychological resources as he/ she notices aspects which he/she needs to improve. In tennis, mental toughness management requires constant adaptation during the training period, derived from planned psychological training aimed at performance improvement, prioritizing permanent adaptation of personality development, self-concept, and emotional control to the competitive needs of each individual player.

KEYWORDS: Self-regulation, emotions, psychological training, personality, tennis.

\section{Treinamento mental do jogador de ténis. Do científico ao aplicado}

RESUMO: Na busca constante para melhora no esporte, o atleta que busca desempenho, realiza avaliações contínuas e reavaliações da sua execução, focalizada no impacto que tais execuções têm para a competição. 0 atleta, quando treina, concentrar-se em procesos de melhora sobre a percepção da sua competência e eficiência no desempenho. Neste artigo expõe-se um planejamento desportivo em jogadores de tênis onde tomam-se en consideração diferentes processos de treinamento psicológico, auto-avaliação contínua do atleta que deverá permitir-lhe tornar-se consciente de seus sinais, a sua ligação pensamento-emoção-comportamento, auto-observação de elementos que irão definir interesses, sinais úteis e prioridades e a auto-percepção da sua gestão global, que influe directamente no desenvolvimento dos seus meios psicológicos segundo observe aspectos a fortalecer dele/dela próprio/própria. 
No tênis, o gerenciamento de fortaleza mental requer duma adaptação constante durante o período de treinamento, derivada de um treinamento psicológico dirigido e planejado para a melhoria de desempenho, priorizando a adaptação permanente do desenvolvimento da personalidade, o auto-conceito e o controle emocional às necessidades competitivas individuais de cada jogador.

PALAVRAS-CHAVE: Auto-regulação, emoções, treinamento psicológico, personalidade, tênis.

Artículo recibido: 10/02/2016 | Artículo aceptado: 22/05/2016

El entrenamiento mental es la práctica habitual de determinadas habilidades psicológicas como estrategias de afrontamiento en situaciones deportivas, tanto de entrenamiento como de competición (Cox, 2012; Riera, Caracuel, Palmi y Daza, 2017; Weinberg y Gould, 2015; Williams y Krane, 2015) Este sistema requiere un trabajo sistemático y aplicado tanto dentro como fuera de los contextos meramente deportivos, al mismo tiempo que valerse de apoyos o refuerzos acordes y actuales que potencien la percepción de sí mismo, la autoconfianza, e incluso despertar la curiosidad para focalizar de una forma correcta hacia objetivos muy concretos. En este trabajo de intervención, se pretende explicar el plan de trabajo llevado a cabo para que el tenista consiga, a través del entrenamiento psicológico, la mejora de sus recursos técnicos y de autogestión mental, en sintonía con trabajos anteriores en otras disciplinas deportivas (González y Garcés de los Fayos, 2009).

Desde el modelo cognitivo-conductual, y más concretamente, desde la Teoría Cognitivo-Social de Bandura (1977), se han venido planteando numerosas estrategias profesionales en el ámbito del deporte, demostrando la implicación entre los niveles de autoeficacia y rendimiento deportivo (Ortega y Meseguer, 2009). Se han encontrado multitud de estudios que relacionan el elevado nivel de autoeficacia con los estados de ánimo, donde se vinculan a la práctica deportiva y emociones como complemento terapéutico o rehabilitador (contextos de salud) (Abenza, Olmedilla, Ortega y Esparza, 2009; Arruza, Arribas, Gil De Montes, Irazusta, Romero y Cecchini, 2008; Bäckmand, Kaprio, Kujala y Sarna, 2009; Fox y Stathi, 2002; Kleinert, 2007; Mainwaring, Hutchison, Bisschop, Comper y Richards, 2010; Nieblas y Molina, 2016), y en número más reducido con el rendimiento deportivo (Arruza, Arrieta y Balagué 1998; Lane, 2008; Lane, Thelwell y Devonport, 2009; Lane et al., 2007; O'Brien y O'Conner, 2000; Scott, Stiles, Raines y Koth, 2002; Terry, 2004).

Las medidas orientadas a los estados y recursos internos del individuo (pensamientos racionales-irracionales, emociones, niveles de atención, etc.) han recibido gran atención por parte de los profesionales del deporte como alternativa a las pruebas de personalidad tradicionales (Godoy, Vélez y Pradas, 2009). Cuando la persona se percibe como altamente capaz para realizar determinada tarea, muestra un gran interés y compromiso, invierte más tiempo y esfuerzo, anticipa resultados, planifica metas, hechos que le permiten al individuo aumentar el esfuerzo requerido para la tarea (González y Garcés de los Fayos, 2014; Uy, Foo y llies, 2015; Vansteenkiste, Lens, Elliot, Soenens y Mouratidis, 2014) y persistir aunque tenga dificultades o adversidades, además de mostrar una mejora en el rendimiento como resultado de un buen proceso de preparación, entendiendo que este concepto de autoeficacia no hace referencia a los recursos de que se disponga, sino a la valoración que se tenga sobre lo que puede hacer con tales recursos.

Viene a dar sentido entonces a la conexión entre el conocimiento y la acción, en el que lo cognitivo media a través de lo que Bandura denomina pensamiento autorreferente. La autoeficacia es el constructo que facilita el determinismo recíproco entre lo psicológico (determinismo personal) y la influencia del ambiente (determinismo ambiental), entre la interpretación de las características de la personalidad y de las contingencias externas de las conductas (Figura 1); entre las creencias en los recursos de afrontamiento y la interpretación de las señales sociales que permitirán ponerlos en marcha.

El desarrollo de estrategias de regulación emocional se ve favorecido mediante la inducción de emociones positivas y la disminución de las emociones negativas, favoreciendo así la mejora del rendimiento deportivo, y como consecuencia, la satisfacción del individuo con su desempeño. (Oriol-Granado, Gomila y Filella, 2014). En el terreno aplicado, ser y estar conscientemente a través de sus estados de ánimo, se ha convertido en una "medida psicológica" que permite mantener al deportista "conectado" a sí mismo, a sus aprendizajes y al proceso de mejora que le genera entrenar y competir en busca de objetivos deportivos. En este sentido, los estados de ánimo se convertirán en referencias psicológicas para fijar objetivos de aprendizaje, de mejora o de reajuste.

Según Beedie (2005), bajo los modelos desarrollados por Lane y Terry (2000) y Morgan (1980), sobre el marco conceptual de los estados de ánimo, señala que existe una 


\section{DETERMINISMO RECÍPROCO}

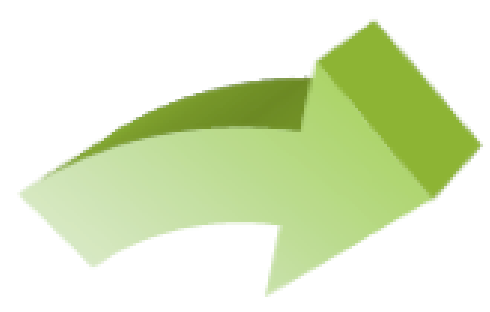

Persona

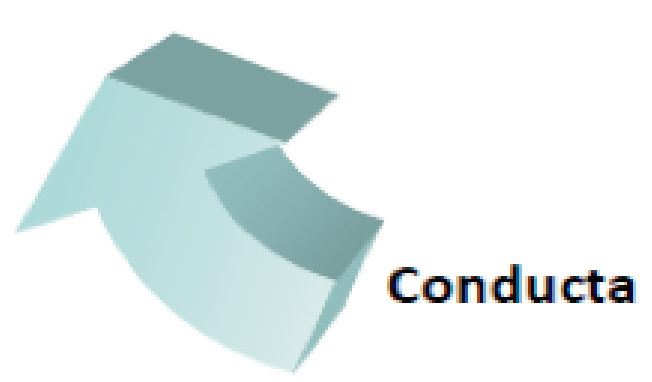

Figura 1. Determinismo recíproco (Bandura, 1977). carencia a nivel teórico que ha conducido a muchas inconsistencias conceptuales y metodológicas con respecto a los estados de ánimo. Lane (2008), lleva a cabo una propuesta explicativa sobre cómo el estado de ánimo influye en el rendimiento deportivo, identificando la necesidad de explicar por qué los factores Tensión y Hostilidad en unos estudios se asocian con buen rendimiento y en otros no. Argumentan que el ánimo depresivo determina el impacto funcional de la tensión y la hostilidad sobre el rendimiento. Sin síntomas depresivos, tensión y hostilidad contribuyen a elevar la determinación, mientras que con síntomas depresivos, contribuyen a ofrecer información que confirma que las dificultades de la tarea están más allá de sus habilidades. Posteriores investigaciones (De la Vega, Ruiz-Barquín, Tejero y Rivera, 2014; Lane, Beddie, Jones, Uphill y Devenport, 2012; Olmedilla, Ortega y Gómez, 2014), apoyan el principio de que el ánimo depresivo es la más importante dimensión anímica debido a su naturaleza desmotivante llegando a la conclusión de su influencia sobre la intensidad de otras dimensiones anímicas.

Al igual que en otros campos de aplicación de la Psicología General, una de las vías para entrenar y desarrollar un proceso consciente en el deportista es la autovaloración de sí mismo, lo que representa una constante imagen viva y dinámica del sujeto sobre sus capacidades, sus metas a alcanzar y sus posibilidades, en un sistema donde se vincula lo cognitivo y afectivo de la personalidad (Cantón, 2016; Sharp, Hodge y Danish, 2014). Tampoco se trata de una simple categorización de productos terminados sobre sí mismo, sino que en la misma se manifiesta una tendencia (en cuanto a su frecuencia, intensidad y orientación) a expresar cualidades necesarias para la realización de cualquier requerimiento técnico, táctico, rutina mental, etc. (esfuerzos mentales y conductuales), en relación con las principales aspiraciones y necesidades de la personalidad, en los que pueden quedar incluidos aspectos que el sujeto desea poseer y que aún no ha logrado, así como elementos ya superados por que se mantienen en su elaboración autovalorativa (Godoy et al., 2009; Sáez, Merino, Ortega y Acebes, 2015).

Una autovaloración adecuada permite en un deportista que este pueda planificar de manera mucho más consciente las acciones técnico-tácticas en pista de manera correcta, las metas y movilización de recursos psicológicos entre e interpuntos, y físicos para desarrollar una buena acciones ofensivas o defensivas en los momentos adecuados. La relevancia en cómo se perciben a sí mismos en cada momento, no sobrevalorará o subvalorará al contrario ni a sí mismos, y ante situaciones de percepción de éxito-fracaso sabrá como continuar de una manera eficaz (González, 2007). Si esta percepción de sí mismo es adecuada o inadecuada, todo lo anterior y posterior influirá de manera positiva o negativa respectivamente, en el rendimiento del deportista.

Desde este punto de vista, el deportista mostrará su grado de implicación (intensidad y fuerza actitudinal con la que un deportista se esfuerza) con el deporte y la vivencia de utilidad del entrenamientos y competiciones que se le plantean para su mejora deportiva, como una consecuencia de factores como la diversión, el esfuerzo personal, percepción de alcanzar un mayor dominio tenístico (sentirse más competente), el reconocimiento social y económico, la interpretación coherente y adecuada de las alternativas contextuales y coacciones sociales, y que todo forma parte de un todo planificado (Riera et al., 2017). En este sentido, algunos autores (Sampaio et al., 2009), sugieren como aspectos claves para desarrollar la implicación del deportista, involucrarles en actividades que presenten la oportunidad de tomar decisiones, desarrollar su sentido de la competencia y conectar con otros deportistas.

\section{Principales factores que influyen en la respuesta psicológica del deportista}

Es necesario profundizar en el estudio y aplicabilidad de las influencias que inciden sobre la respuesta emocional de los deportistas a la hora de manejar sus pensamientos y conductas (Gill, Williams y Reifsteck, 2017). En el comportamiento tenístico, el tenista se enfrenta a jugadas de cambio permanente, en continua toma de decisiones, con 
exigencias de atención mantenida y activación equilibrada. En este sentido, Barrios (2007) indica una breve descripción acerca de los principales factores presentes en la actividad cotidiana del tenista:

- De acuerdo a las características de la actividad, se pueden apreciar problemáticas vinculadas a la asimilación de cargas; las tareas peligrosas, difíciles y con requerimientos complejos de coordinación; cambios de técnica, evento, división o categoría; interrupciones del proceso de preparación (lesiones, enfermedades); problemas de peso corporal y adaptación a diversas circunstancias que se convierten en barreras psicológicas; preocupaciones por lesiones, etc.

- Aparecen nuevas problemáticas en cada etapa de preparación. En la pre-competición, concebida como una adaptación a las condiciones de la competición, se puede alterar el nivel de excitación y control emocional y ello está determinado por la importancia atribuida a las competencias, objetivos, exigencias externas, personalidad y valoración de insuficiencias en la preparación. En la competición se presentan situaciones complejas que se suceden de manera impredecible, y causan alteraciones como excitación, ira, rivalidad, optimismo, pesimismo ante resultados adversos y otros. Esta etapa expresa el grado de preparación emocional alcanzado y la dirección de la intervención psicológica en el futuro inmediato. En la etapa post-competitiva se presentan vivencias de éxito o fracaso, con consecuencias positivas y negativas para el estado anímico y la conducta posterior del atleta: optimismo, confusión, desánimo; ira, inquietud, insatisfacción, preocupaciones por lesiones o por las consecuencias del desempeño deportivo.

Todos los recursos mencionados (gestión emocional, habilidades de autorregulación y autoobservación, desarrollo de creencias limitantes o potenciadoras, recursos para el autodiálogo y el juicio interno,...), forman parte de las variables trabajadas de manera planificada y progresi- va, conjuntamente con entrenadores, e integradas en una sistema de entrenamiento, donde la mejora de los factores psicológico, configuran una parte importante del progreso tenico-táctico de los jóvenes tenistas.

Siguiendo los planteamientos científicos como Cross (1999) o Hajibaklo, Arjmandnia, Dosti y Hasani (2015), en el siguiente trabajo se propone y se expone la metodología de entrenamiento mental llevado a cabo con tenistas de iniciación, amateurs y profesionales. Se trata de una metodología aplicada, basada en evidencia científica, resultado de experiencias profesionales de psicólogos deportivos, ofreciendo un diseño de actuación protocolarizado.

\section{Experiencia profesional}

El presente trabajo, es el fruto de una metodología planificada de entrenamiento psicológico con tenistas, tanto de formación como de alto rendimiento. La relación con los mismo, se realiza a través del Instituto Deportivo de Salud y Deporte, Innova ubicado en la ciudad de Murcia (España). La importancia de un trabajo continuado de entrenamiento psicológico se ha materializado en un trabajo para el desarrollo de recursos mentales en el tenista (personalidad, autoconocimiento y gestión interna de características psicológicas), y siendo más específicos, principalmente para la mejora de la percepción de la autoeficacia y autogestión (autorregulación y autoobservación) de los 15 tenistas con los que se lleva un plan de entrenamiento psicológico durante más de un año.

Las edades comprendidas son entre 20 y 14 años, lo que supone trabajar con tenistas en categorías cadete y junior del circuito español de tenis. Las sesiones se desarrollan tanto en pista como en sala, alternando el trabajo individual y grupal a lo largo del desarrollo de las sesiones. (Tabla 1).

Anteriormente, y durante una primera fase inicial diagnóstica se establecen diferentes metodologías (observación en dentro y fuera de la pista, registros de creencias y rutinas, entrevistas tenistas, entrenador y padres, entre otras,...) para

Tabla 1. Características de tenistas y planificación estructural

\begin{tabular}{|c|c|c|c|}
\hline $\mathbf{N}^{\mathrm{a}}$ tenistas: 15 & \multicolumn{2}{|c|}{ Duración de las sesiones: 60 min. } & Modalidad: Pista y sala \\
\hline Edades & 4 cadetes: $14-15$ años & 6 juveniles: $16-18$ años & 5 junior: $18-20$ años \\
\hline Sesiones de trabajo individuales & 1/semana & 1/quincena & 1/quincena \\
\hline Sesiones de trabajo grupal & \multicolumn{3}{|c|}{$1 /$ mes } \\
\hline Total sesiones año & 40 & 20 & 20 \\
\hline
\end{tabular}


determinar las variables psicológicas prioritarias a la hora de orientar el plan de entrenamiento (autodiálogo, concentración, niveles atencionales, gestión de la presión emocional, etc..), así como se plantean estrategias para desarrollar una identidad común entre los componentes del grupo de tenistas (sentido de sentirse tenista) (Bossio, Raimundi y Correa, 2012; Del Valle y Pozo, 2010; Nieto y Olmedilla, 2001). Todo ello con la pretensión del cumplimiento de los siguientes objetivos específicos inmersos en todo el proceso de trabajo (Figura 2):

- Generar una dirección adecuada de pensamiento ganador para generar el mayor y óptimo rendimiento en el momento de la competición.

- Construir junto al jugador un esquema de las metas realistas que tiene para el deporte (metas a largo plazo) y para la competición (metas a corto plazo).

- Comenzar con el entrenamiento básico de recursos y estrategias mentales, que permitan configurar y habituar la base de la respuesta psicológica, que posteriormente se convertirá en automática a través del proceso que combine repetición-interpretación-comprensión.

- Establecer sistema de evaluación continua, que faciliten el acceso a la información mental y de juego. Combinando elementos que permitan la información "a tiempo real" e inmediato (autorregistros, percepción subjetiva del esfuerzo, etc.) con otros que se centren en una información parcial que permita la proyección (suposiciones, concreciones, invenciones creativas, etc.) y la estimulación de los recursos intuitivos (esenciales para el tenista en su rendimiento).
Teniendo en cuenta trabajos como el de González y Garcés de los Fayos (2009), Godoy et al., (2009), Lochbaum y Gottardy (2015), Riera et al. (2017), Sharp et al. (2014) y Wylleman (2000), se establecen los procesos de recogida de información, priorización de procesos, planificación secuencial de sesiones y reporte de la información, contemplando procesos como el de la individualización del deportista (Foltz, et al., 2015).

\section{Objetivos del plan y proceso del entrenamiento psicológico}

- Llegar al deportista. Primera toma de contacto con el deportista. (sin papeles por delante, sin otro afán que ganarse su confianza y la de su entrenador, padres, etc.).

- Conocer la realidad existente. Evaluación general y objetiva ¿Qué sucede y por qué? Comprobar (mediante instrumentos de evaluación adaptados a cada deporte, aquellas habilidades más importantes que el deportista y su entorno creen que necesitan o de aquellas de las que no son conscientes de su importancia para practicar su deporte), observar (para tener constancia de conductas del deportista y de su entorno) y comparar (para establecer de forma más objetiva las necesidades del deportista y del entorno que influye sobre su rendimiento).

- Decidir cómo se debe actuar para mantener o modificar esa realidad. ¿Qué variables potenciar y cuáles disminuir o neutralizar para aumentar el rendimiento? (Establecimiento de objetivos del entrenamiento psicológico).

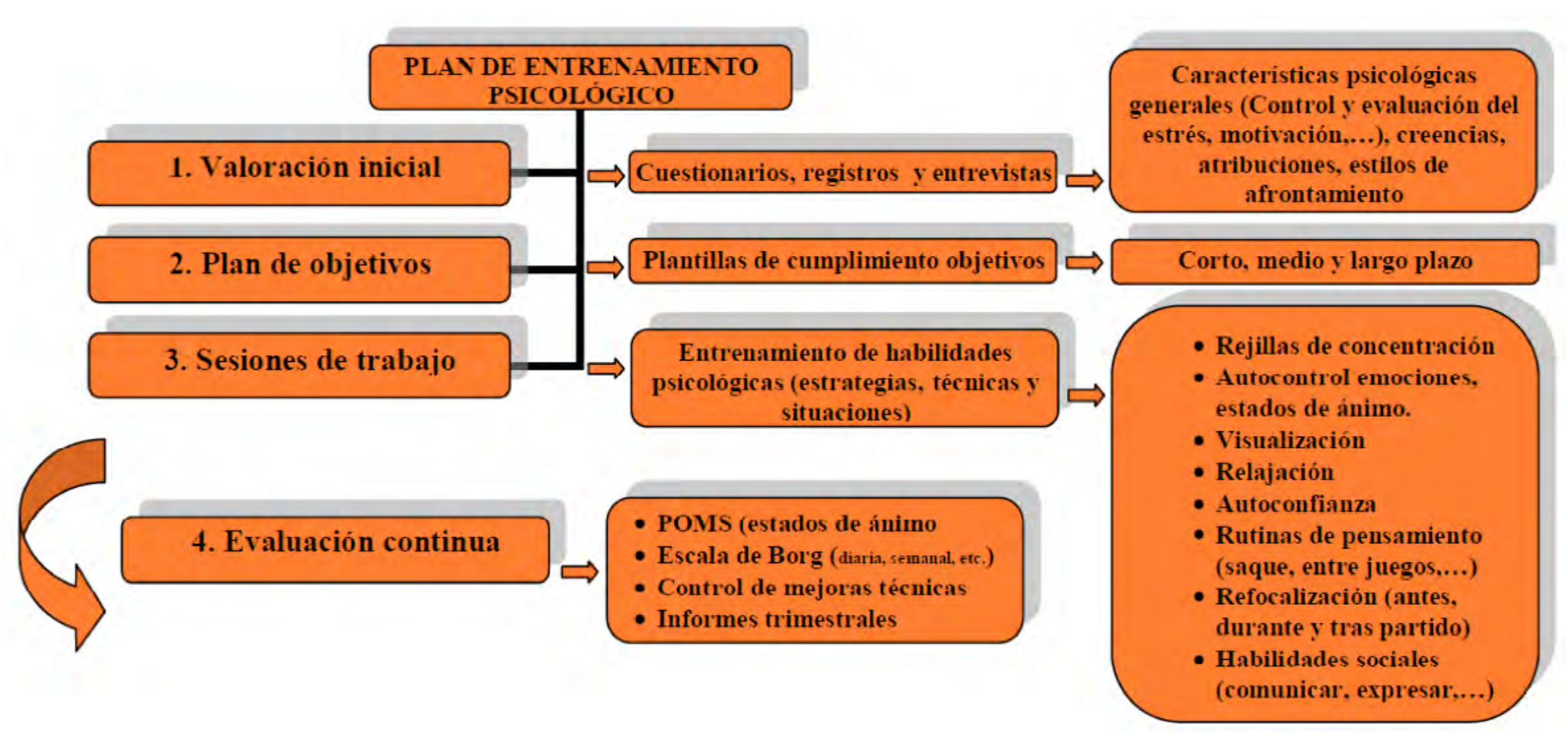

Figura 2. Esquema del plan de entrenamiento psicológico llevado a cabo. 
- Diseño y puesta en marcha de un plan de entrenamiento psicológico. Programación de las distintas actividades a realizar para la conseguir los objetivos establecidos. Partiendo de la objetividad ya evaluada hacia unos objetivos realistas, alcanzables y motivantes para el deportista y su entorno.

- Controlar o valorar la eficacia de la intervención (Diseño y establecimiento de sistemas de evaluación continua). Observar los efectos y resultados que se van consiguiendo sobre las conductas trabajadas.

\section{Valoración psicológica y deportiva de los tenistas}

Para el presente trabajo, se lleva a cabo una evaluación psicológica y deportiva en la que se pretenden medir todas y cada una de las variables psicológicas que predisponen la percepción del entorno deportivo en general y el competitivo en particular. Es por ello que se valoran las características psicológicas generales como la Motivación, Habilidad Mental, el Control de la Ansiedad y Percepción de Estrés, con el cuestionario CPRD (Gimeno, Buceta y Pérez-Llantada, 2012) o IPED (Raimundi, Reigal y Hernández Mendo, 2016); percepción de éxito, con el Cuestionario de percepción de éxito POSQ, elaborado por Roberts y Balagué (1991); creencias, con el Cuestionario de Creencias sobre las Causas que llevan al Éxito en el Deporte CCCED (Duda y Nicholls, 1992); estilos de afrontamiento, con el Inventario de Estilos de Afrontamiento CSI (Cano, Rodríguez y García, 2007).

\section{Elaboración y puesta en marcha del plan de objetivos de trabajo}

Es en esta parte del proceso, donde debe construirse junto al jugador un esquema de las metas que tiene en la competición (metas a medio plazo) y a continuación detallar todas aquellas metas diarias a las que debería ir llegando para alcanzar su máximo rendimiento y aumentar la probabilidad de alcanzar sus metas a largo plazo (metas a corto plazo) (De la Vega, Ruiz-Barquín, Del Valle, Garcia-Mas, Olmedilla y Balagué, 2008).

Una adecuada forma de prepararse mentalmente es pensar en los propios objetivos y qué es lo que se está haciendo para lograrlos. ¿Qué quiero cumplir hoy? Puede ser conveniente anotar esos objetivos y hacerlos correr a través de la mente. Hay que buscar formas simples y efectivas para ponerse mentalmente listos para entrar en una zona con calidad focal para lograr los objetivos diarios (Figura 3). De este modo conseguiríamos dirigir la atención y la acción del

\section{$\underline{\text { Plan de entrenamiento }}$}

Fecha

Semana $\mathbf{n}^{\circ}$ :

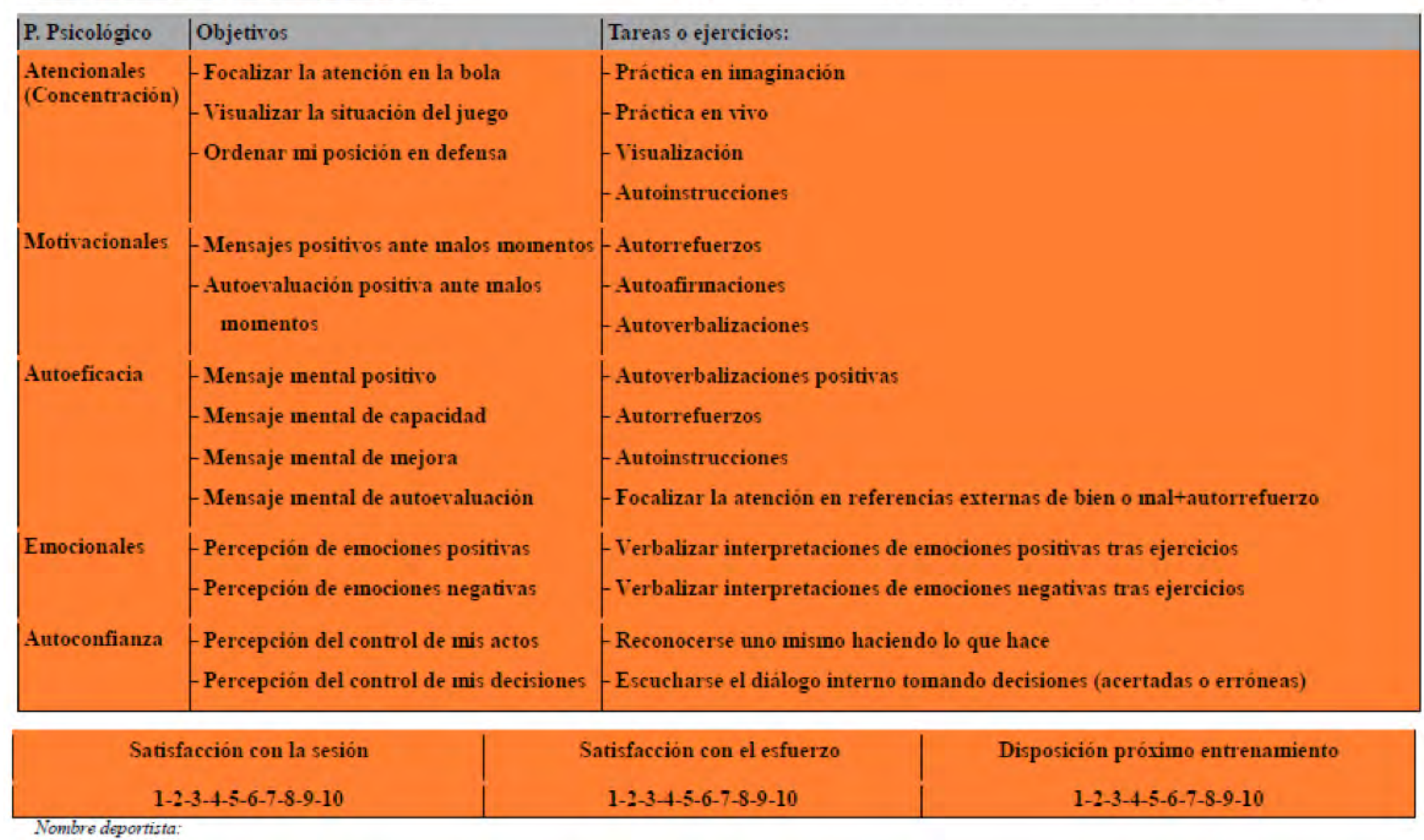

Figura 3. Plan de establecimiento y cumplimiento de objetivos. 
jugador a los aspectos relevantes de la tarea y producir un nivel óptimo de confianza, disminución de la ansiedad, mayor motivación y una mejora de la ejecución al establecerse metas realistas que se pueden ir consiguiendo en espacios relativamente cortos de tiempo (Arruza et al., 1998, González y Garcés de los Fayos, 2009; González Campos, Valdivia-Moral, Zagalaz Sánchez y Romero Granados, 2015).

Para ello, apoyarse en tablas de planteamiento de objetivos en las que se reflejan todas aquellas tareas diarias que nos aportarán un conocimiento real de nuestro propio rendimiento y que ayudarán a focalizar los aspectos más importantes de la ejecución individual con unos índices mayores de autoconfianza y autocontrol (González y Garcés de los Fayos, 2009; Olmedilla, Ortega, Ortín y Andreu, 2010; OlmediIla y Dominguez-Igual, 2016).

Generar una dirección adecuada de pensamiento ganador para generar el mayor y óptimo rendimiento en el momento de la competición, se incluye en un plan de acción que facilita al tenista una automatización de movimientos, pensamientos y emociones esencial para un aprendizaje continuo y una práctica de alto nivel (De la Vega, et al., 2008; Sharp et al., 2014).

\section{Desarrollo de sesiones de trabajo}

En este sentido, los planes de acción positivos incluyen imágenes positivas, pensamientos de ampliación de la confianza, y recordatorios específicos de exactamente lo que quiere hacer y cómo poder focalizar mejor para hacerlos (Figura 4). Los ejercicios se pueden realizar de manera conjunta entre el psicólogo deportivo y el entrenador, tanto en sala como en pista (García-Naveira, 2016; Lochbaum y Gottardy, 2015).

Además, para valorar la eficacia de la puesta en práctica de lo entrenado psicológicamente, se definn una serie de objetivos de ajuste psicológico para trabajar en la pista con ellos y posteriormente a observar en la competición; en este sentido, planteamos:
La mayoría de los ejercicios y tareas a conseguir por cada uno de los tenistas en el trabajo psicológico, se plantean combinados en sus ejercicios con objetivos técnico-tácticos (Serre, Martín, Cabanellas y Vargas, 2014), siendo de gran relevancia que integren en sus esquemas conceptuales, mecanismos cognitivos que gradualmente se van incorporando desde la sala a la pista, para ello, debemos generar una habituación en la que funcionamiento psicológico, técnico y táctico deben encontrarse en la misma sintonía (Figura 5). En este sentido, una vez planteado el trabajo psicológico integrado en los ejercicios de entrenamiento cotidianos, debemos observar la consecución de lo entrenado, estableciendo correcciones y adaptaciones permanentes y graduales al modo de juego de cada tenista (Cross, 1999; Olmedilla et al., 2010; Sáenz-López, Jiménez, Giménez y Ibáñez, 2007).

Al mismo tiempo, la utilización de sesiones de video como técnica complementaria de observación y feedback, permite conocer y analizar las características de utilización de cada uno de los gestos técnico-tácticos en el entorno real de juego, así como del trabajo cognitivo-conductual; transfiriendo lo que observamos a rutinas y conductas en los entrenamientos en pista, para hacer estos más específicos y aplicados a la realidad de la competición (Ortega, Olmedilla y Giménez, 2008).

Al final de la sesión, la aplicación de técnicas de visualización potencia estos aspectos en los jugadores individualmente, fijando además los conocimientos adquiridos con disparadores cognitivos (palabras, imágenes, sonidos, rutinas,...), y facilitan el traspaso de creencias, percepciones y conductas desarrolladas del entrenamiento a la competición (Del Valle y Pozo, 2010; Olmedilla et al., 2010; Ortega et al., 2008).

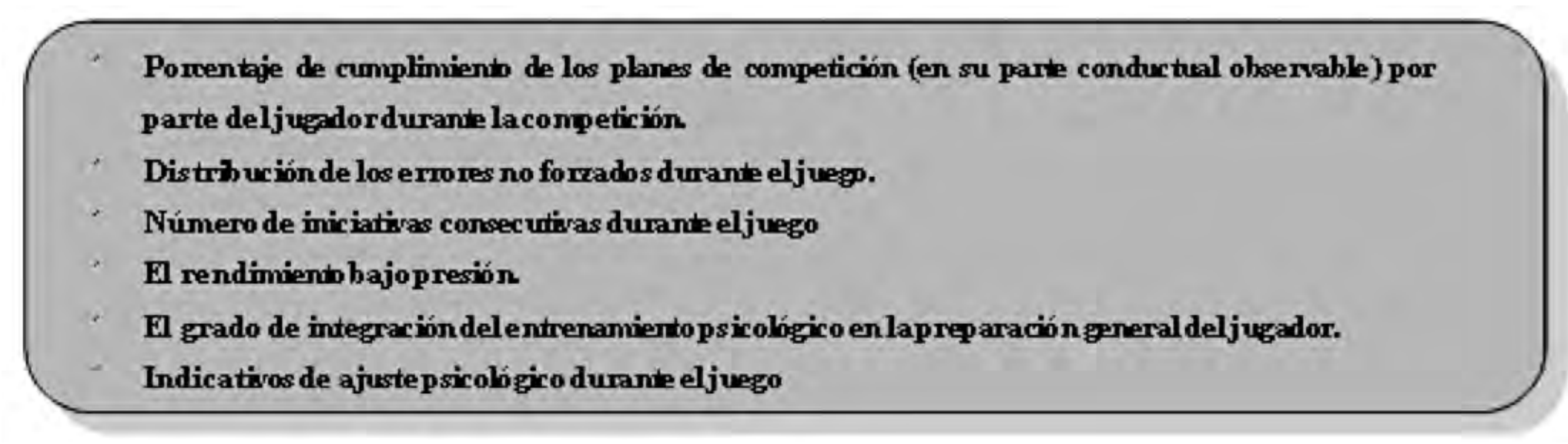

Figura 4. Objetivos de ajuste y a observar entrenamientos y competiciones. 


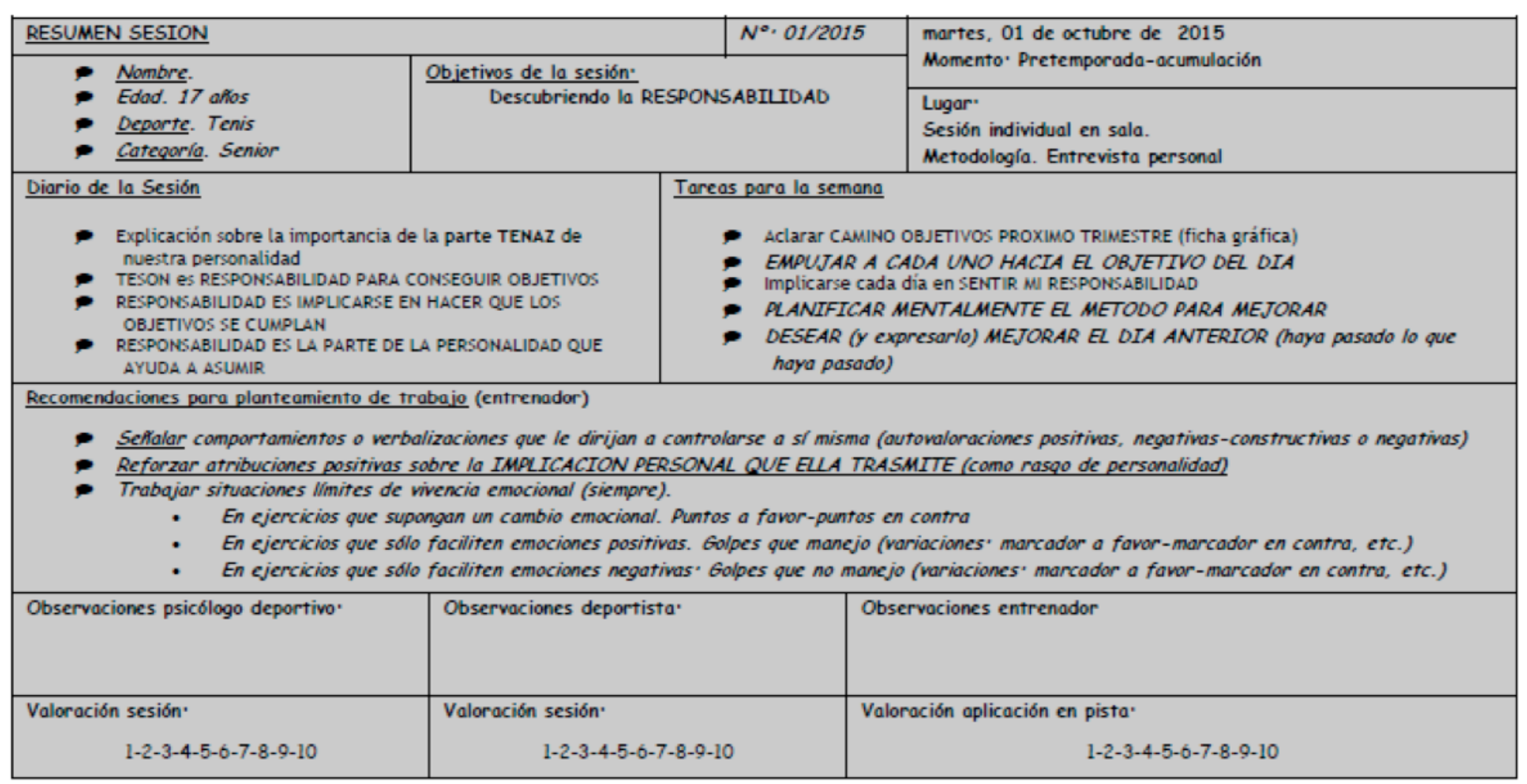

Figura 5. Ficha de sesiones y entrenamiento psicológico.

\section{Evaluación continua del proceso de trabajo psicológico}

Para mantener un proceso de evaluación continua con los tenistas, se recomienda que con una periodicidad (aproximadamente cada 3-4 semanas), la medición de diferentes habilidades o recursos psicológicos que permitan al deportista mantener una mayor, constante y útil información o conocimiento sobre la base establecida inicialmente en los perfiles, entre las que pueden destacarse: estados de ánimo (POMS; Andrade, Arce, Armental, Rodríguez y De Francisco, 2008; Andrade, Arce y Seoane, 2002; Fernández, Fernández y Pesqueira, 2002; Morgan, 1980) (Figura 6), motivación intrínseca y extrínseca (SMS, Brière, Vallerand, Blais y Pelletier, 1995), toma de decisiones (CETD, Ruiz y Graupera, 2005), resiliencia (CD-RISC, Connor y Davidson, 2003), entre otras variables que facilitan útiles reportes de información, permitiendo orientar y/o reorientar por el propio deportista y sus entrenadores partes de entrenamientos y planteamientos de competidores - (metodologías observacionales).

La evaluación de programas de entrenamiento psicológico, como en el resto de las áreas de entrenamiento, permite dirigir la atención a diferentes aspectos del proceso de enseñanza aprendizaje, por lo que de forma periódica el equipo de trabajo (entrenadores-psicólogo) mantiene reuniones y emiten informes de estado, y de consecución de objetivos técnicos, psicológicos y competitivos (Figura 7). Con ello, el equipo técnico (entrenadores y psicólogo deportivo) relaciona las ideas de referencia (la programación) y la evolución

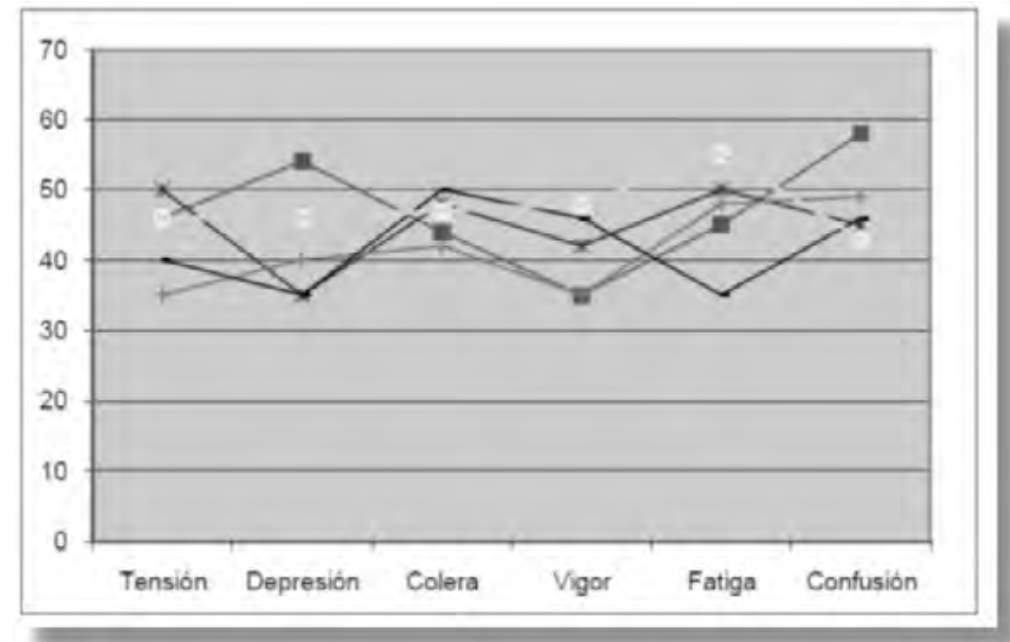

Figura 6. Registro del POMS

de la práctica (el desarrollo de los entrenamientos y competiciones), favoreciendo el establecimiento de conexiones significativas entre el funcionamiento cognitivo, vivencia emocional y aplicación conductual, ayudando en suma, a tomar decisiones más acertadas y a disponer de una metodología permanente de autoevaluación de indicadores de mejora (González y Garcés de los Fayos, 2009). 


\begin{tabular}{|c|c|c|}
\hline ES & - & $\begin{array}{l}\text { Fecha: } \\
\text { Momento: Pretemporada-acumulación }\end{array}$ \\
\hline & $\begin{array}{l}\text { Objetivo } \\
\text { FUNCIONAR COMO UN VERDADERO EQUIPO }\end{array}$ & $\begin{array}{l}\text { Lugar: Sala de reuniones } \\
\text { EQUIPO DE TRABAJO (entrenodor-psicólogo) } \\
\text { Metodología. COORDINAR Y PLANIFICAR }\end{array}$ \\
\hline \multicolumn{3}{|c|}{$\begin{array}{l}\text { Tareas para la semana (Para todos) } \\
\text { Aclarar CAMINO OBJETIVOS PROXIMO TRIMESTRE (ficha gráfica). POR ESTE ORDEN: } \\
\text { DEPORTIVOS (marcarán el estilo de juego, los aspectos técnicos y tácticos, los detalle a mejorar en el juego del dia a dia, y ayudarán a } \\
\quad \text { FISICOS (ayudarán a Laura a sention bien su cuerpo, a reconocer puntos fuertes y débiles en el plano físico y que pueda crecer sobre ellos) } \\
\quad \text { COMPETIIIVOS (son los que marcarán la intensidad, exigencia, esfuerzo y dirección del resto de objetivos) } \\
\text { PSICOLOGICOS (facilitarán la adaptación permanente de la forma de vivir el resto de objetivos. Sin una claridad de los otros, estos no } \\
\text { tendrán sentido o no serán eficaces) }\end{array}$} \\
\hline \multicolumn{3}{|c|}{ 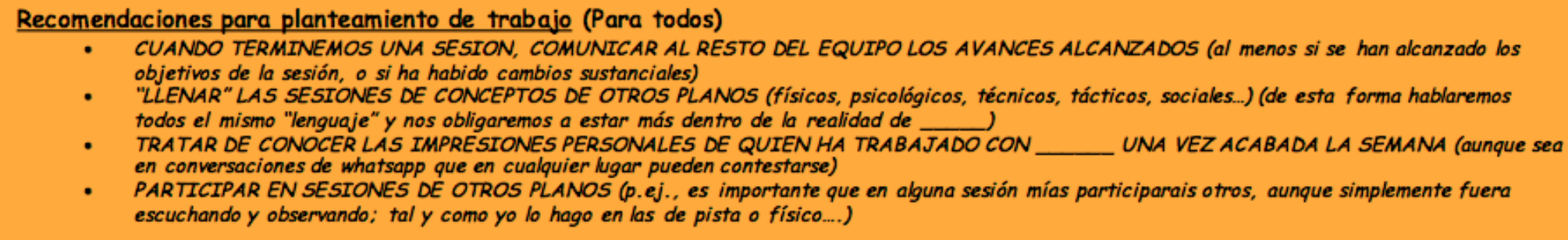 } \\
\hline \multicolumn{3}{|c|}{ 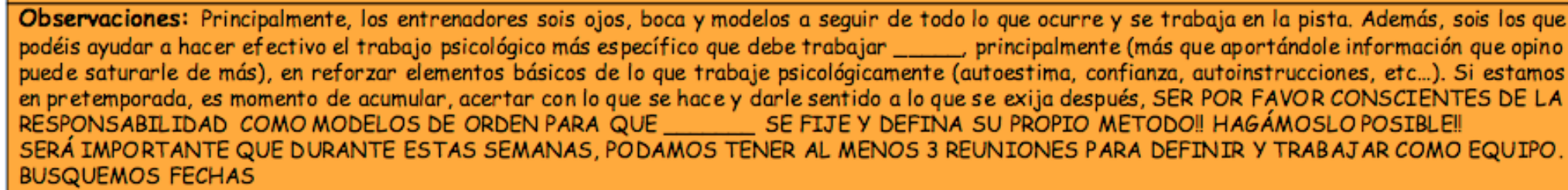 } \\
\hline
\end{tabular}

Figura 7. Ficha de sesiones coordinación equipo técnico (entrenadores-psicólogo).

\section{Competición: posibilidad de autoajuste psicológico}

Durante la competición es más que relevante comprobar si los aspectos trabajados van siendo efectivos en cada uno de los tenistas fijados individualmente y con las orientaciones establecidas en las sesiones de entrenamiento.

En la propia competición, es necesario un trabajo de refocalización permanente del propio tenista hacia información precisa de dichas observaciones, incluso en el caso de un jugador que pierde la tranquilidad a lo largo del juego, también es posible que el mismo deportista reconduzca mediante el uso de la mismas técnicas de visualización, relajación o rutinas previamente entrenadas durante el periodo de entrenamiento, siendo bastante efectiva esa intervención (puntual autoaplicación) en el rendimiento posterior de ese jugador, siempre y cuando el proceso se haya llevado de forma correcta (González y Garcés de los Fayos, 2009; Pérez-Recio, 1996).

La necesidad de la observación se hace patente en los momentos competitivos, ya que es cuando el tenista, en su máxima expresión competitiva, ofrece los mejores argumentos para la interpretación de su respuesta psicológica y conductual (González, 2007; Latinjak, Álvarez y Renom, 2009; Serre et al., 2014), así como de la puesta en escena de hábitos y rutinas mentales (repasar las líneas, respiraciones inter-puntos, imaginación guiada, balanceo pre-saque, ritmo intrapunto, etc.) que permiten los recursos de autorregulación durante el juego.

\section{Discusión}

El proceso de entrenamiento llevado a cabo, pretende llevar al deportista a alcanzar un "estado de forma mental", señalado por el nivel de entrenamiento psicológico, presentando unas características bien definidas que permitirán al psicólogo ajustar el control de las respuestas del deportista a las cargas de entrenamiento (González y Garcés de los Fayos, 2009).

Precisamente, el sistema de entrenamiento aquí expuesto, ha resultado eficaz a lo largo de la temporada en la que se ha llevado a cabo, siendo un pilar esencial en la evolución tenística de cada uno de los deportistas. La oportunidad de planificar a lo largo de la temporada, de una manera completa desde el inicio, permite contemplar todos los aspectos del entrenamiento psicológico, tanto desde el punto de vista preparatorio y preventivo (pre-competición), a lo largo de la misma atendiendo a las circunstancias que surgen en el proceso competitivo, y los caminos que se abren tras la misma (post-competición) donde el tenista valora sus progresos no sólo competitivos ( $n^{\circ}$ partidos, ranking, etc.) sino de mejora técnica (golpes, posiciones, etc.), estratégica (manejo de situaciones de partido a favor, en contra, rutinas de saque, etc.), físicos (resistencia, duración de partidos, etc.) y psicológicos (capacidades de concentración, autoinstrucciones, anticipación mental, etc.).

En el contexto tenístico de competición, tanto en el alto rendimiento deportivo como en los programas de tecnifica- 
ción deportiva existe una constante búsqueda de los medios para lograr cada vez mejores resultados, insistiendo en los controles del entrenamiento y de la competición (Martínez-Duarte, 2006; Ortega et al., 2008; Ortiz, 2004; Palmi, 2007; Santos Rosa, García, Jiménez, Moya y Cervelló, 2007). Se determinan claramente los objetivos, y su consecución o no es el criterio de éxito. Si tenemos en cuenta que las emociones regulan el funcionamiento mental, organizando tanto el pensamiento como las acciones, tendremos que tenerlas muy en consideración para el funcionamiento psicológico en cualquier momento del proceso deportivo (precompetición, competición y postcompetición).

Los tenistas y entrenadores de alto nivel, y los que aspiran a ello, deberán caracterizarse por tener una habilidad equilibrada tanto para expresar emociones como para identificarlas en modos contextualmente adecuados, ya que en el modelo competitivo actual, la persona percibe estados emocionales muy intensos que debe ser capaz de autorregular de forma permanente. (Lorenzo y Sampaio, 2007; Pérez, 2002; Santos Rosa et al, 2007)

Las emociones proporcionan información acerca de nuestras reacciones ante las situaciones. Muchas son el resultado de evaluaciones automáticas que hacemos sobre el significado de las relaciones sobre nuestro bienestar, los deportistas en general, y en el juego del tenis en particular, con numerosa frecuencia, se enfrentan ante situaciones que les generan constantes estados de malestar-bienestar (López, 2006; Nieblas y Molina, 2016).

Los programas de entrenamiento no son ni exactos ni efectivos al $100 \%$, son propuestas de trabajo que hay que adaptar en todo momento a las características de los deportistas. En este caso, los tenistas han tenido una individualización de los procesos, conforme sus características de juego y de recursos psicológicos. Precisamente, afinar con las cualidades a trabajar en cada momento, se convierte en una limitación a lo largo de todo el proceso, ya que el reajuste constante, exige una dedicación que en ocasiones no se ajusta a las necesidades el entrenamiento. Este aspecto, supone una complicación mayor, en los momentos más cercanos a la competición, donde todo parece ocurrir más deprisa, con sensaciones de falta de tiempo y donde todo se experimenta de manera mucho más determinante, tanto en la interpretación de los éxitos como de los fracasos.

\section{Aplicaciones prácticas}

La gran mayoría de los tenistas deben regular sus estados mentales y emocionales en el que se encuentran inmersos en los momentos de puntos decisivos (un saque con punto de break, un cambio de ritmo, p.ej.) introduciendo al mismo en una vivencia subjetiva (positiva o negativa). Es en esos momentos, cuando deben sentirse capaces de "soltarse" de su proceso emocional y dejar fluir toda su ejecución. Es el mismo tenista, el principal protagonista a la hora de activarse y darse cuenta, reconociendo sus indicadores del equilibrio cognitivo-emocional y valorando la situación de una forma intensa en la que focaliza su atención (refocalización).

En ese estado, el tenista aprovecha el estado de alerta generado, mejorando también su velocidad de reacción (anticipación), se facilita alejarse o apoyarse en la emoción para superarse ese momento, o al menos, esa es la pretensión aplicada de la metodología de trabajo propuesta en la realización del entrenamiento mental descrito. Por esa misma razón, la información que el tenista descubre en sí mismo, llegada de sus respuestas psicológicas internas, es la más valiosa para conectar su esfuerzo con sus objetivos, reconociendo el valor de los mismos, fortaleciendo las creencias que ha construido en cuanto a la utilidad que esos objetivos tienen para su crecimiento personal, y potenciando en todo momento la capacidad de alcanzar el proceso de manera autónoma (competente) y el sentido del trabajo que supone trabajar por ello.

Previamente, el trabajo de entrenamiento psicológico debe conducir a la interiorización e introspección de gran cantidad de recursos mentales, que ayudan al tenista a canalizar sus procesos de autogestión. Las capacidades que permiten el desarrollo aplicado del aprendizaje autorreferente - (sobre si mismo), y que a su vez construyen madurativamente posibilidades cognitivas determinantes para sus
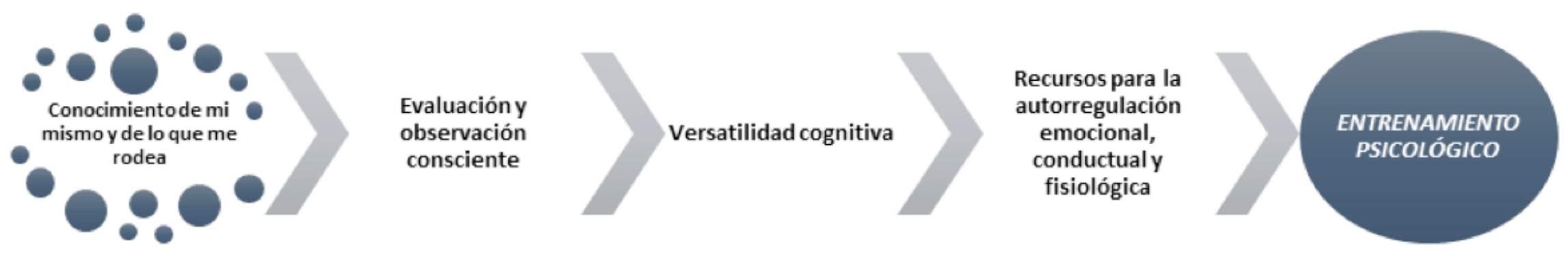

Figura 8. Proceso de entrenamiento de recursos psicológicos en el tenista. 
procesos motivacionales y su manera de actuar (Figura 8). Potenciar sus capacidades para convertirlos en proactivos, con capacidades para la autorregulación en situaciones de presión y toma de decisiones son objetivos esenciales de este plan de entrenamiento psicológico, donde el deportista crece a través de lo que practica y pone en juego todas las cualidades psicológicas entrenadas, aprovechándolas para su mejora competitiva (Tabla 2). mación fluya de manera útil, se convierte en una herramienta tan importante como lo puede ser la transmisión al tenista de los referentes sobre sus mejoras. Tanto psicólogo como entrenadores, reportando y conectando las necesidades de los tenistas, individualizarán sus estrategias, sus mensajes y sus observaciones, para que cada tenista entienda "su juego" y sus evoluciones en la pista y fuera de ella.

\section{Tabla 2. Descripción de la evolución psicológica del tenista}

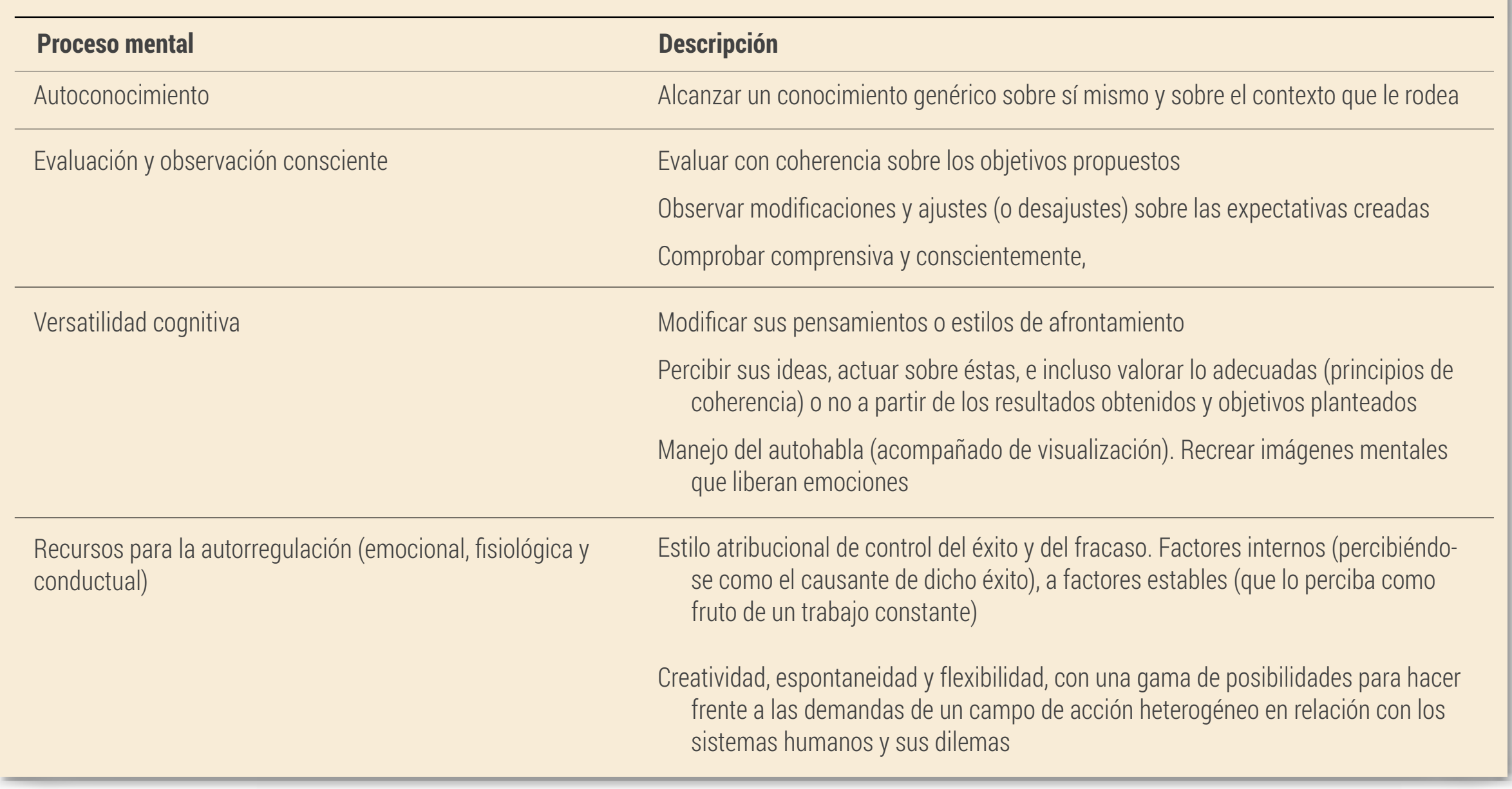

El aprendizaje de estos procesos, permitirá a los entrenadores comprender mucho más las estrategias y objetivos en las metodologías de entrenamiento-competición que trabajan con sus tenistas, las cualidades y recursos que sus tenistas ponen en juego para alcanzar la adaptación coherente a sus ritmos, aceptando la individualización o acertando en la enseñanza de los mismos, así como a valerse del trabajo del profesional de la psicología deportiva, que con base científica ofrece posibilidades a entrenador y tenistas para un entrenamiento psicológico integrado, coherente, progresivo, y mantenido en todo momento para los requerimientos y exigencias deportivas, desde los inicios de la trayectoria deportiva de un joven tenista y hasta la élite, en su caso.

La esencial coordinación con los entrenadores, permitirá la coherencia entre todos los objetivos propuestos para cada tenista. Establecer canales abiertos, donde la infor-

\section{Referencias}

Abenza, L., Olmedilla, A., Ortega, E. y Esparza, F. (2009). Estados de ánimo y adherencia a la rehabilitación de deportistas lesionados. Apunts. Medicina de l'Esport, 44, 161, 29-37.

Andrade, E. M., Arce, C., Armental, J., Rodríguez, M. y De Francisco, C. (2008). Indicadores del estado de ánimo en deportistas adolescentes según el modelo multidimensional del POMS. Psicothema, 20, 630-635

Andrade, E. M., Arce, C. y Seoane, P. G. (2002). Adaptación al español del cuestionario "Perfil de los Estados de Ánimo" en una muestra de deportistas. Psicothema, 14, 708-713.

Arruza, J. A., Arribas, S., Gil De Montes, L., Irazusta, S., Romero, S. y Cecchini, J. A. (2008). The impact of duration in sport and physical activity on the psychological well-being. Revista Internacional de Medicina y Ciencias de la Actividad Física y el Deporte, 8(30), 171-183.

Arruza, J. A., Arrieta, M. y Balagué, G. (1998). Rendimiento deportivo e influencia del estado de ánimo, de la dificultad estimada, y de la autoeficacia en la alta competición. Revista de Psicología del Deporte, 7, 193-204. 
Bäckmand, H. M., Kaprio, J. K., Urho M. y Sarna, S. (2009). Physical activity, mood and the functioning of daily living: A longitudinal study among former elite athletes and referents in middle and old age. Archives of Gerontology and Geriatrics, 48(1), 1-9.

Bandura, A. (1977). Self-efficacy: Toward a Unifying theory of behavioral change. Psychological Review, 2, 191- 215.

Barrios, R. (octubre, 2007). Los estados de ánimo en el deporte: fundamentos para su evaluación II. Revista Digita efdeportes. com 12, 113. Recuperado de http://www.efdeportes.com/ efd173/los-estados-de-animo-en-el-deporte.htm

Beedie, C. J. (2005). It's the POMS, it measures mood-Doesn't it. In T. Morris (Chair), Promoting health and performance for life: International Society of Sport Psychology (ISSP). Symposium conducted at the meeting of the 11th World Congress of Sport, Sydney Convention and Exhibition Centre.

Bossio, M. R., Raimundi, M. J. y Correa, L. G. (2012). Programa de entrenamiento en habilidades psicológicas en jugadoras de voleibol de alto rendimiento. Cuadernos de Psicología del Deporte, 12(1), 9-16.

Brière, N., Vallerand, R., Blais, N. y Pelletier, L. (1995). Développement et validation d'une mesure de motivation intrinsèque, extrinsèque et d'amotivation en context sportif : I'Échelle de motivation dans les sports (ÉMS). International Journal of Sport Psychology, 26, 465-489.

Cano, F. J., Rodríguez, L. y García, J. (2007). Adaptación española del Inventario de Estrategias de Afrontamiento. Actas Españolas de Psiquiatría, 35, 1, 29-39.

Cantón, E. (2016). La especialidad profesional en Psicología del Deporte. Revista de Psicología Aplicada al Deporte y el Ejercicio Físico, 1, e2. https://doi.org/10.5093/rpadef2016a2

Connor, K. M. y Davidson, J. R. (2003). Development of a new resilience scale: The Connor-Davidson resilience scale (CDRISC). Depression and Anxiety, 18(2), 76-82.

Cox, R. H. (2012). Sport Psychology: Concepts and Applications (7.a ed). Nueva York, Estados Unidos: McGraw Hill Education.

Cross, N. (1999) Individualization of training programmes. En N. Cross and J. Lyle, (Eds.) The Coaching Process: Principles and Practice for Sport (pp. 174-191). Oxford, Reino Unido: Butterworth Heinemann.

De la Vega, R., Ruiz-Barquín, R., Tejero C. y Rivera M. (2014). Relación entre estados de ánimo y rendimiento en voleibol masculino de alto nivel. Revista de Psicología del Deporte, 23(1), 49-56.

De la Vega, R., Ruiz-Barquín, R., Valle, S. D., Garcia-Mas, A., Olmedilla, A. y Balagué, G. (2008). Consistencia y fluctuación de los estados de ánimo en un equipo de fútbol profesional durante una competición de play off. Revista de Psicología del Deporte, 17, 241-251.

Del Valle, C. F. y Pozo, R. H. (2010). Efecto de una intervención psicológica breve sobre la ejecución futbolística profesional. Mexican Journal of Behavior Analysis, 36(1), 99-116.

Duda, J. L. y Nicholls, J. G. (1992). Dimensions of achievement motivation in scholwork and sport. Journal of Educational Psychology, 84, 290-299.

Fernández, E. M., Fernández, C. A. y Pesqueira, G. S. (2002). Adaptation of the profile of mood states into Spanish with a sample of athletes. Psicothema, 14, 708-713.
Foltz, B. D., Fisher, A. R., Denton, L. K., Campbell, W. L., Speight, Q. L., Steinfeldt, J. y Latorre, C. (2015). Applied sport psychology supervision experience: A qualitative analysis. Journal of Applied Sport Psychology, 27, 449-463.

Fox, K. R. y Stathi, A. (2002). Physical activity and mental health in older adults: Current evidence and future perspectives. Psychology: The Journal of the Hellenic Psychological Society, 9, 563-580.

García-Naveira, A. (2016). Área de Psicología de la Real Federación Española de Atletismo: programación y desempeño profesional. Cuadernos de Psicología del Deporte, 16, 251-258.

Gill, D., Williams, L. y Reifsteck, E. (2017). Psychological dynamics of sport and exercise. Champaign, IL, Estados Unidos: Human Kinetics.

Gimeno, F., Buceta, J. M. y Pérez-Llanta, M. D. C. (2012). El cuestionario "Características Psicológicas Relacionadas con el Rendimiento Deportivo»(CPRD): Características psicométricas. Análise Psicológica, 19(1), 93-113.

Godoy, D., Vélez, M. y Pradas, F. (2009). Nivel de dominio de las habilidades psicológicas en jóvenes jugadores de tenis de mesa, bádminton y fútbol. Revista de Psicología del Deporte, 18, 7-22.

González, J. (2007). Herramientas aplicadas al desarrollo de la concentración en el alto rendimiento deportivo. Cuadernos de Psicología del Deporte, 7(1), 61-70.

González, J. y Garcés de los Fayos, E. J. (2009). Plan de entrenamiento psicológico en el deporte de la petanca: en búsqueda del rendimiento grupal óptimo. Revista de Psicología del Deporte. 18, 87-104.

González, J. y Garcés de los Fayos, E. J. (2014). Diferencias individuales e indicadores de ansiedad como estrategias adaptativas de auto-eficacia en el deportista. Ansiedad y Estrés, 29, 57-59.

González Campos, G., Valdivia-Moral, P., Zagalaz Sánchez, M. L. y Romero Granados, S. (2015). La autoconfianza y el control del estrés en futbolistas: revisión de estudios. Revista Iberoamerciana del Ejercicio y el Deporte, 10(1), 95-101.

Hajibaklo, A., Arjmandnia, H., Dosti, M. y Hasani, S. (2015). Designing Training Structure and its Relation with Sport Skill Acquisition with Emphasis on Athletes' Individual Differences. Turkish Journal of Scientific Research, 2(5), 126-132.

Kleinert, J. (2007). Mood states and perceived physical states as short-term predictors of sport injuries: Two prospective studies. International Journal of Sport and Exercise Psychology, 5, 340-351.

Latinjak, A. T., Álvarez, M. T. y Renom, J. (2009). Aplicando el auto-habla al tenis: su impacto sobre el foco atencional y el rendimiento. Cuadernos de Psicología del Deporte, 9(2), 19-21.

Lane, A. M. (2008). Mood and sport performance. Sport and exercise psychology: Topics in applied psychology. Lane, Andrew M. (Ed.) (pp. 19-34); London, Reino Unido: Hodder Education Group.

Lane, A. M., Beddie, C. J., Jones, M. V., Uphill, M. y Devenport, D. J. (2012). The Bases expert statement on emotion regulation in sport. Journal of Sport Sciences, 30, 1189-1195.

Lane, A. M. y Terry, P. C. (2000). The nature of mood: Development of a conceptual model with a focus on depression. Journal of Applied Sport Psychology, 12, 16-33. 
Lane, A. M., Thelwell, R. y Devonport, T. J. (2009). Emotional intelligence and mood states associated with optimal performance. E-Journal of Applied Psychology, 5(1), 67-73.

Lane, A.M., Whyte, G. P., George, K., Shave, R., Stevens, M. J. y Barney, S. (2007). Marathon: A fun run? Mood state changes among runners at the London marathon. Mood and human performance: Conceptual, measurement and applied issues. Andrew, M. Lane (Ed.) (pp. 261-270). Hauppauge, NY, Estados Unidos: Nova Science Publishers.

Lochbaum, M. y Gottardy, J. (2015). A meta-analytic review of the approach-avoidance achievement goals and performance relationships in the sport psychology literature. Journal of Sport and Health Science, 4(2), 164-173.

López, M. R. (2006). Características y relaciones de "Flow", ansiedad, y estado emocional con el rendimiento deportivo en deportistas de élite. (Tesis Doctoral no publicada).

Lorenzo, A. y Sampaio, J. (2005). Reflexiones sobre los factores que pueden condicionar el desarrollo de los deportistas de alto nivel. Apunts. Educación Física y Deportes, 80, 63-70

Mainwaring, L. M., Hutchison, M., Bisschop, S. M., Comper, P. y Richards, D, W. (2010). Emotional response to sport concussion compared to ACL injury. Brain Injury, 24, 589-597.

Martínez-Duarte, M. (2006). Planificación deportiva de una escuela de iniciación al baloncesto. Benjamines 8-10 años. Recuperado de http://www. efdeportes.com/efd101/bc.htm

Morgan, W. P. (1980). The Trait Psychology Controversy. Research Quarterly for Exercise and Sport, 57, 50-76.

Nieblas, J. y Molina, P. (2016). Revisión sistemática de la investigación sobre la enseñanza del tenis. Cuadernos de Psicología del Deporte, 16(2), 111-124.

Nieto, G. y Olmedilla, A. (2001). Planificación del entrenamiento psicológico en atletas de élite: un caso en marcha atlética. Revista de Psicología del Deporte, 10, 127-142.

O'Brien, P. M. y O'Conner, P. J. (2000). Effect of bright light on cycling performance. Medicine \& Science in Sports \& Exercise, 32, 439-447.

Olmedilla, A. y Domminguez-Igual, J. J. (2016). Entrenamiento psicológico para la mejora de la atención y la autoconfianza en un futbolista. Revista de Psicología Aplicada al Deporte y el Ejercicio Físico, 1, e4. https://doi.org/10.5093/rpadef2016a4

Olmedilla, A., Ortega, E. y Gómez, J. M. (2014). Influencia de la lesión deportiva en los cambios del estado de ánimo y de la ansiedad precompetitiva en futbolistas. Cuadernos de Psicología del Deporte, 14(1), 55-62.

Olmedilla, A., Ortega, E., Ortín, F. J. y Andreu, M. D. (2010). Programa de intervención psicológica en futbolistas. Revista de Psicología del Deporte, 19, 249-262.

Oriol-Granado, X., Gomila, M. y Filella, G. (2014). Regulación emocional de los resultados adversos en competición. Estrategias funcionales en deportes colectivos. Cuadernos de Psicología del Deporte, 14(1), 63-72.

Ortega, E. y Meseguer, M. (2009). Análisis de la autoeficacia percibida, el rendimiento y la participación en jugadores de baloncesto en edad de formación y la relación con la percepción de eficacia de sus entrenadores. Información Psicológica, 97, 17-26

Ortega, E., Olmedilla, A. y Giménez J. M. (2008). Utilización del video para la mejora de la percepción subjetiva de la eficacia competitiva y del rendimiento en jugadores de baloncesto. Revista de Psicología del Deporte, 18, 279-290.

Ortiz, R. H. (2004). Tenis. Potencia, velocidad y movilidad. BarceIona, España: INDE Publicaciones.

Palmi, J. (2007). La percepción: enfoque funcional de la visión. Apunts. Educación Física y Deportes 88, 81-85.

Pérez, M. C. (2002). Caracterización del entrenador de alto rendimiento deportivo. Cuadernos de Psicología del Deporte, 2(1), 15-37.

Pérez-Recio, G. (1996). Aplicaciones de la psicología al tenis de alto nivel. Apunts. Educació Física i Esports, 4(44-45), 136-142.

Raimundi, M. J., Reigal, R. E. y Hernández Mendo, A. (2016). Adaptación argentina del Inventario Psicológico de Ejecución Deportiva (IPED): validez, fiabilidad y precisión. Cuadernos de Psicología del Deporte, 16(1), 211-222.

Riera, J., Caracuel, J. C., Palmi, J. y Daza, G. (2017). Psychology and Sport: The athlete's self-skills. Apunts. Educació Física i Esports, 127(1), 82-93.

Roberts, G. C. y Balagué, G. (1991). The development and validation of the Perception of Success Questionnaire. Trabajo presentado en el Congreso FEPSAC, Cologne, Alemania

Ruiz, L. M. y Graupera, J. L. (2005). Dimensión subjetiva de la toma de decisiones en el deporte: Desarrollo y validación del cuestionario CETD de estilo de decisión en el deporte. Motricidad, 14, 95-107.

Sáenz-López, P., Jiménez, A. C., Giménez, F. J. e Ibáñez, S. J. (2007). La autopercepción de las jugadoras de baloncesto expertas respecto a sus procesos de formación. Ciencia, Cultura y Deporte, 7(3), 35-41.

Sáez, G., Merino, M., Ortega, R. y Acebes, J. (2015). Análisis de la ansiedad antes de la competición en el Campeonato de Madrid de primera categoría femenina de pádel. Revista Andaluza de Medicina del Deporte, 8(4), 188-189.

Sampaio, J., Lorenzo, A., Gómez, M. A., Matalarranha, J., Ibáñez, S. J. y Ortega, E. (2009). Análisis de las estadísticas discriminantes en jugadores de baloncesto según su puesto específico, en las finales de las competiciones europeas (1988-2006). Diferencias entre jugadores titulares y suplentes. Apunts. Educación Física y Deportes, 96, 53-58.

Santos-Rosa, F. J., García, T., Jiménez, R., Moya, M. y Cervelló, E. M. (2007). Predicción de la satisfacción con el rendimiento deportivo en jugadores de tenis: efecto de las claves situacionales. Motricidad. European Journal of Human Movement, 18, 41-60.

Sharp, L. A., Hodge, K. y Danish, S. (2014). Sport psychology consulting at elite sport competitions. Sport, Exercise, and Performance Psychology, 3(2), 75

Scott, V. B., Stiles, K. B., Raines, D.B. y Koth, A. W. (2002) Mood, rumination, and mood awareness in the athletic performance of collegiate tennis players. North American Journal of Psychology, 4, 457-468.

Serre, N. B., Martín, C. T., Cabanellas, R. P. y Vargas, F. S. L. (2014). Entrenamiento integrado. Principios dinámicos y aplicaciones/Integrated Training. Dynamic principles and applications. Apunts. Educació Física i Esports, 176, 60.

Terry, P. C. (2004) Mood and emotions in sport. En T. Morris y J. Summers, (Eds.). Sport psychology: Theory, applications and 
issues. ( ${ }^{\mathrm{a}}$ Ed., pp. 48-73). Milton, QLD, Australia: John Wiley \& Sons Australia.

Uy, M. A., Foo, M. D. y llies, R. (2015). Perceived progress variability and entrepreneurial effort intensity: The moderating role of venture goal commitment. Journal of Business Venturing, 30, 375-389.

Vansteenkiste, M., Lens, W., Elliot, A. J., Soenens, B. y Mouratidis, A. (2014). Moving the achievement goal approach one step forward: Toward a systematic examination of the autonomous and controlled reasons underlying achievement goals. Educational Psychologist, 49(3), 153-174.
Weinberg, R. S. y Gould, D. (2015). Foundations of Sport and Exercise Psychology (6.a ed.). Champaigne, II, Estados Unidos: Human Kinetics.

Williams, J. y Krane, V. (2015). Applied Sport Psychology. Personal growth to peak performance (7.a ed.). Nueva York, Estados Unidos: McGraw Hill Educations.

Wylleman, P. (2000). Interpersonal relationships in sport: Uncharted territory in sport psychology research. International Journal of Sport Psychology, 37, 555-572. http://dx.doi.org/10.1016/j.psychsport.2005.08.001 